\title{
O espírito livre de Nietzsche e o gênio de Schopenhauer: um paralelismo*
}

\author{
Laura Langone**
}

Resumo: Este artigo tem o objetivo de mostrar as semelhanças entre o espírito livre de Nietzsche e o gênio de Schopenhauer. Em primeiro lugar, ambos compartilham de uma abordagem mística do conhecimento: perdem sua individualidade e identificam-se aos objetos do conhecimento com o intuito de obter conhecimento do mundo. Em segundo lugar, ambas as figuras (gênio e espírito livre) encontram-se associadas à loucura. Em terceiro lugar, o espírito livre e o gênio são indivíduos excepcionais que, diferentemente do que se passa com a maior parte dos indivíduos, já não se encontram atrelados a questões mundanas. Conduzem-se na vida pacificamente, pairando sobre os valores em que as pessoas mais acreditam, cientes de sua falsidade.

Palavras-chave: arte, mística, experimentação, individualidade, vontade, Ideias.

\footnotetext{
* Tradução de Saulo Krieger

** University of Cambridge, Cambridge, Inglaterra. ORCID: https://orcid.org/0000-0002-6467-7577

Correio eletrônico: 11544@cam.ac.uk
} 
Langone, L.

\section{O espírito livre de Nietzsche}

A filosofia do espírito livre é uma fase específica da filosofia de Nietzsche, que inclui as obras Humano, demasiado humano, A gaia ciência e Aurora. A figura do espírito livre é por ele definida no aforismo 225 de Humano, demasiado humano, intitulado "O espírito livre, um conceito relativo":

É chamado de espírito livre aquele que pensa de modo diverso do que se esperaria com base em sua procedência, seu meio, sua posição e função, ou com base nas opiniões que predominam em seu tempo. Ele é a exceção, os espíritos cativos são a regra: estes lhe objetam que seus princípios livres têm origem na ânsia de ser notado ou até mesmo levam à inferência de atos livres, isto é, inconciliáveis com a moral cativa (MM/HH § 225, KSA 2.189).

Nietzsche contrasta a figura do espírito livre com a do assim chamado "espírito cativo". Este é o que aceita de maneira acrítica todos os valores tradicionais que a sociedade transmite mediante moralidade, metafísica, religião e arte. Seu espírito é cativo à medida que, não sendo capaz de pensar por si mesmo, limita-se a seguir a maioria. Ele é um produto de seu ambiente, de sua classe e de sua profissão, das visões dominantes de seu tempo.

Em vez de tomar por naturais e certos os valores em relação aos quais a maior parte das pessoas se mostra concorde, o espírito livre investiga as razões pró e contra. Ele deseja investigar a sua proveniência, deseja compreender por que certos valores são aceitos e outros não. Adota certos valores após uma investigação crítica, e não por serem compartilhados pela maioria das pessoas. Ele é capaz de desenvolver com autonomia seus próprios pensamentos e concepções sobre o mundo, sem ser influenciado pela sociedade.

Assim, por exemplo, este axioma: a moralidade não é outra coisa (e, portanto, não mais!) do que obediência a costumes, não importa quais sejam; mas costumes são a maneira tradicional de agir e avaliar. Em coisas nas quais 
nenhuma tradição manda não existe moralidade; e quanto menos a vida é determinada pela tradição, tanto menor é o circuito da moralidade (M/A $\S 9$, KSA 3.21-22).

A sociedade apresenta seus valores morais como verdadeiros para toda a eternidade: eles não são postos em questão, uma vez que foram passados de geração em geração. Valores são verdadeiros por pertencerem à tradição, e tradições têm existido desde a aurora dos tempos. Tradição e moralidade são a mesma coisa, e, por essa razão, para a sociedade não faz sentido questioná-los. Fazê-lo é como se questionássemos a própria civilização, tudo o que construímos ao longo da história.

Estando no seio de uma tradição, a moralidade exerce seu comando em todos os campos de nossa vida; ela já estabeleceu de uma vez por todas o modo como conduzimos nossa vida, prescrevendo maneiras de agir com relação à educação, casamento, cura de doenças, agricultura, guerra, discurso etc. E exerce seu comando porque aparece a seres humanos como um poder indefinido, como autoridade elevada e de origens misteriosas. Temendo o desconhecido, os seres humanos simplesmente a obedecem, sem se perguntar sobre sua natureza.

Contudo, os valores tradicionais espelham os interesses da sociedade e não os dos indivíduos, eles foram criados pela sociedade para que se perseguissem seus próprios objetivos. São valores para a sociedade. Segue-se daí que o espírito cativo que aceita de maneira acrítica os valores tradicionais é um escravo da sociedade, à medida que não persegue seus próprios interesses, mas os da sociedade. $\mathrm{O}$ espírito livre, pelo contrário, é livre porque se comporta de acordo com seus próprios pensamentos e valores.

Sendo os valores algo de tão vital para a existência da sociedade, cada vez que na história houve indivíduos que não agiram de acordo com o costume, grande punição recaiu sobre toda a comunidade. Desse modo, receosa das punições, a maioria das pessoas aprendeu a 
Langone, L.

obedecer o costume sem nenhuma hesitação. No entanto, sob certas circunstâncias violações de costumes eram aceitas pela sociedade. Isso acontecia quando vinham da parte de loucos.

Se, apesar da terrível pressão da 'moralidade do costume', sob a qual viveram todas as comunidades humanas, por muitos milênios antes de nosso calendário, e também, no conjunto, até os dias de hoje [...], ideias, valorações, instintos novos e divergentes, isso ocorreu em horripilante companhia: em quase toda parte, é a loucura que abre alas para a nova ideia, que quebra o encanto de um uso e uma superstição venerados. (M/A $\S 14, \mathrm{KSA} 3.26)$.

$\mathrm{Na}$ Antiguidade, somente aos loucos era permitido expressar ideias e avaliações que se voltassem contra os costumes. A razão para tal era a de que à época as pessoas acreditavam que a loucura seria algo divino, que onde quer que houvesse loucura haveria um grão de genialidade e sabedoria. Em outras palavras, os loucos eram tidos em alta conta, uma vez que a eles se atribuía uma condição divina.

Por essa razão, as pessoas que quisessem expressar sua individualidade, suas próprias convicções tinham de se fingir loucas para evitar repercussões sociais. Na maioria dos casos, adotavam uma dieta específica para assumir a aparência de um louco. Sob certas circunstâncias, porém, em razão dessa dieta acabavam ficando realmente loucas.

As receitas para se tornar louco eram quase as mesmas em diferentes civilizações, fosse as dos cristãos da Idade Média, ou a dos gregos, dos groenlandeses ou dos brasileiros: “jejum absurdo, prolongada abstenção sexual, ir para o deserto ou subir numa montanha ou num pilar ou 'pôr-se num velho salgueiro com vista para um lago' e não pensar em nada que não produzisse arrebatamento e confusão espiritual" (M/A § 14, KSA 3.26)

Nesse sentido, no passado o espírito livre tinha de assumir o disfarce do homem louco para expressar suas próprias visões sobre o mundo. Em vez de tomar como certas as concepções da 108 | Cad. Nietzsche, Guarulhos/Porto Seguro, v.41, n.1, p. 105-119, janeiro/abril, 2020. 
sociedade porque a tradição ordena que, em sua condição de espírito agrilhoados, eles assim o façam, ao buscar as razões pró e contra, o espírito livre questiona tais concepções, experimentando-as. "Eu elogio todo ceticismo ao qual eu possa responder: 'Tentemos!' Mas já não quero ouvir falar de todas essas coisas e questões que não permitem o experimento" (FW/GC § 51, KSA 3.415-416).

O espírito livre não age de acordo com um conjunto específico de valores, quais sejam, os da sociedade. Para descobrir os seus próprios valores, os valores que espelham a sua personalidade, ele decide fazer experimentos com todos os valores elaborados pela humanidade ao longo de sua história. Desse modo, a experimentação se faz o caminho para o conhecimento do espírito livre.

Isso significa que o espírito livre encarna os valores tradicionais em sua própria pele: em vez de simplesmente tomá-los como dados, ele os põem em prática a fim de ver a quais resultados práticos eles conduzem. Procura a todo o tempo viver de acordo com valores diferentes: depois de ter agido de acordo com um valor, adota outro valor e assim por diante.

Como um viandante que a todo o tempo viaja de um lugar a outro, ele a todo momento muda de ponto de vista. Ele é muitos indivíduos ao mesmo tempo, pois encarna os valores de muitos indivíduos, sendo todos valores que a humanidade criou ao longo da história.

Um homem do qual caíram os costumeiros grilhões da vida, a tal ponto que continua a viver tão-somente para conhecer sempre mais, deve poder renunciar, sem inveja e desgosto, a muita coisa, a quase tudo o que tem valor para os outros homens; deve-lhe bastar, como a condição mais desejável, pairar livre e destemido sobre os homens, costumes, leis e avaliações tradicionais das coisas (MA I/HH I Para tranquilizar 34, KSA 2.55).

Ao final desse caminho para o conhecimento, depois de ter experimentado com todos os valores da tradição, o espírito livre 
Langone, L.

chega ao conhecimento de sua natureza, descobrindo a razão por trás de tais valores. Tem a consciência de que esses valores todos não são verdadeiros em si mesmos e de que, por essa razão, eles não possam ser adotados por toda a eternidade. E termina no deserto do niilismo, onde já nada faz sentido.

Por isso uma cultura superior deve dar ao homem um cérebro duplo, como que duas câmaras cerebrais, uma para perceber a ciência, outra para o que não é ciência; uma ao lado da outra, sem se confundirem, separáveis, estanques; isto é uma exigência da saúde. Num domínio a fonte de energia, no outro o regulador: as ilusões, parcialidades, paixões devem ser usadas para aquecer, e mediante o conhecimento científico deve-se evitar as consequências malignas e perigosas de um superaquecimento. (MA I/HH I § 251, KSA 2.209)

Enquanto a maior parte das pessoas vive em paz, convencida de que suas crenças são verdadeiras para toda a eternidade, o espírito livre pode apenas pairar [schweben] por sobre a moralidade, sobre os costumes, sobre as leis, ciente de sua falsidade. Contudo, os seres humanos têm uma necessidade natural de metafísica, de moralidade, religião e arte. Não conseguem viver sem elas. Por isso, após ter descartado a metafísica, a moralidade, a religião e a arte, o espírito livre pode sempre ficar tentado a nelas buscar refúgio.

Para evitá-lo, ao espírito livre se tem de permitir, por vezes, desfrutar dos prazeres da metafísica, da moralidade, da religião e da arte. De outro modo, seu progresso estará em perigo. Por um lado, metafísica, moralidade, religião e arte são narcóticos perigosos: ao suscitar um prazer estando na dor, tais narcóticos impedem-nos de confrontar as causas de nosso infortúnio e de eliminá-las. Por outro lado, uma vez que os seres humanos não podem viver sem elas [metafísica, moralidade, religião e arte], uma cultura mais elevada tem de proporcionar ao espírito livre uma espécie de cérebro duplo, de modo que por meio desse cérebro ele possa realizar sua investigação 
acerca da natureza dos valores, enquanto por meio do outro cérebro sente prazer com metafísica, moralidade, religião e arte.

\section{O gênio de Schopenhauer e suas semelhanças com o espírito livre de Nietzsche}

Nietzsche e Schopenhauer têm duas visões opostas sobre a arte. Enquanto Nietzsche, na fase de sua filosofia do espírito livre, critica veementemente a arte, considerando-a um narcótico, Schopenhauer, ao contrário, entende-a como a mais autêntica forma de conhecimento. Antes de analisar as semelhanças entre o espírito livre e o gênio, deve-se ter isso em mente. A presente seção visa fazer ver que, não obstante as claras diferenças na avaliação geral do papel da arte na vida, há notáveis semelhanças entre as principais características do espírito livre e as do gênio louvadas por Schopenhauer.

Por um lado, a arte para Nietzsche, como forma da metafísica, impede-nos de ter acesso ao conhecimento autêntico, que pode ser atingido unicamente por meio da experimentação. Por outro lado, para Schopenhauer o conhecimento objetivo é estético: ele pode ser obtido em caráter excepcional, tão só por meio da arte. Aquele que é capaz de obtê-lo é o chamado gênio. O gênio é o artista que pode apreender as Ideias, as formas originais e imutáveis de tudo o que existe no mundo. Tomando-se esse quadro como um todo, tem-se a vontade: uma entidade metafísica imutável apresentada indivisa tanto em corpos orgânicos quanto nos inorgânicos.

A vontade é essencialmente vontade de vida, anseio contínuo. Ela constantemente anseia por satisfazer seus desejos infinitos, estando, porém, destinada a se manter insatisfeita: tão logo um desejo é satisfeito, outro surge, e assim por diante. Uma vez que a verdade jamais é satisfeita, ela se caracteriza por sofrimento. A vontade é anseio contínuo, e o anseio conduz à dor.

Uma vez que a essência do ser humano é vontade, ele vive num mundo de sofrimento. Após ter satisfeito um desejo, cai presa 
Langone, L.

do tédio até ter um novo desejo para satisfazer, e assim por diante. Portanto, sua vida é caracterizada por sofrimento e monotonia, que são dois lados da mesma moeda: a vontade.

A vontade é a coisa em si mesma, o único ser verdadeiro, e tudo o quanto vemos no mundo, incluindo a nós mesmos, é um fenômeno, mera aparição da vontade. Os fenômenos constituem o mundo da aparência: surgem e se esvanecem, não têm existência intrínseca, só o que existe sendo a vontade, que é eterna e imutável.

$\mathrm{Na}$ verdade, não existem fenômenos, não existem coisas simples, mas tão-somente a vontade. $\mathrm{O}$ ser humano não é capaz de apreender a realidade da vontade porque ele vivencia o mundo necessariamente por meio do principium individuationis, por meio das formas a priori de seu intelecto como espaço, tempo e causa, que concebem o mundo como dividido em espaço, tempo e como habitado por indivíduos.

Em razão do principium individuationis, o ser humano não vê o mundo como ele realmente é, mas como aparece: o mundo é sua representação. De modo geral, a representação é um objeto para um sujeito. $\mathrm{O}$ mundo objeto existe à medida que existe um sujeito a postulá-lo. O objeto pressupõe sempre um sujeito. Isto significa que nós percebemos o mundo tal qual é postulado pelas formas $a$ priori de nosso intelecto, não como é em si mesmo.

A depender da adequação na objetificação da vontade, existem vários graus de representação. Os fenômenos encontram-se num nível mais baixo, enquanto no topo estão as Ideias. As Ideias são a "objetidade imediata" da vontade, a cópia mais adequada da vontade. Enquanto fenômenos são fugazes, as Ideias são eternas.

Em razão do principium individuationis, o ser humano via de regra só é capaz de apreender fenômenos. É o principium individuationis que multiplica as Ideias em fenômenos particulares e temporais. Esse modo de ver as coisas por meio de tal princípio é 
o caminho da experiência e da ciência. Ele é útil para se lidar com os assuntos da vida diária, mas está longe da verdade.

Graças à ciência, ao longo de toda a história a humanidade pôde se libertar do jugo dos fenômenos naturais. Por meio do conceito de causa, o ser humano aprendeu a prever esses fenômenos. Ocorre que a ciência não é capaz de ir além do conceito de causa. Ela busca sempre pela causa de um fenômeno e, após descobri-lo, busca pela causa dessa causa e assim por diante, terminando por examinar a infinita cadeia de causas.

A ciência não pode afirmar algo de definitivo sobre um objeto, pode apenas dizer de que modo ele acontece na experiência, e não o que é em sua essência. Ela pode se debruçar sobre as relações causais entre objetos no espaço e tempo, mas não sobre o objeto tomado em si mesmo.

Bem em sentido contrário, a arte isola o objeto do fluxo dos assuntos mundanos, a fim de contemplá-los. Não leva em conta as relações entre objetos, mas tão-somente a Ideia do objeto. Para o artista, só existe o objeto tomado em si, como se ele estivesse além de espaço e tempo. Enquanto a ciência jamais cessa de buscar pelas causas dos fenômenos, a arte faz parar a roda do tempo, permanecendo em repouso com o seu objeto.

Mas arte e ciência têm também algo em comum: ambas lidam com unidades que representam uma multiplicidade de coisas reais, Ideias e conceitos, respectivamente. Contudo, há profundas diferenças entre eles.

Em primeiro lugar, a Ideia é a unidade original que o principium individuationis multiplica em muitos fenômenos, enquanto os conceitos são unidades construídas por nossa razão mediante um processo de abstração. Em segundo lugar, os conceitos são indeterminados no âmbito de suas esferas, o que é compreensível a todo aquele que estiver de posse da razão. As ideias, pelo contrário, não obstante representarem um número infinito de coisas, são completamente 
Langone, L.

determinadas. São de todo intuitivas e podem ser apreendidas tãosomente por gênios.

Assim sendo, enquanto "o conceito se assemelha a um receptáculo morto, no qual tudo o que se põe fica efetivamente lado a lado, de onde, porém, nada pode ser retirado [...] senão o que se pôs", a Ideia, ao contrário, "desenvolve em quem a apreendeu representações que são novas em relação ao conceito que lhe é homônimo" (Schopenhauer, 2010, p. 261).

As Ideias podem ser apreendidas somente em casos excepcionais, uma vez que deveríamos ser capazes de nos libertar do principium individuationis que é nosso modo em comum de olhar para as coisas. Isso acontece quando o intelecto se liberta do controle da vontade. Trata-se de um estágio bastante excepcional, dado que ele é a vontade que criou o intelecto tão-só para perseguir os seus próprios objetivos. Via de regra, o intelecto é o escravo da vontade, só mesmo o gênio podendo momentaneamente reverter essa condição.

Quando elevados, pela força do espírito, a deixar de ver as coisas pelo modo corriqueiro, não mais conduzidos pelas formas do princípio de razão suficiente, visando buscar meramente relações entre as coisas [...] nós de todo nos perdemos nos objetos, isto é, esquecemos nossa individualidade, nossa vontade, e continuamos a existir somente como puro sujeito, o espelho claro do objeto, como se o objeto existisse por si próprio, sem ninguém que o percebesse, de modo que não mais podemos separar o intuído da Intuição, pois afinal ambos se tornaram um só (Schopenhauer, 2010, p. 201)

O gênio é aquele capaz de temporariamente ignorar seus próprios interesses e desejos e dedicar-se de modo pleno à contemplação das Ideias. Ele não mais é capaz de um anseio individual para satisfazer seus desejos, tendo se tornado sujeito cognitivo puro, um sujeito sem objetivo pessoal, cuja única atividade está em contemplar as Ideias.

Na condição desse puro sujeito cognitivo, ele é capaz de, por momentos, ir além de espaço e tempo e identificar-se inteiramente com os objetos de contemplação. Ao contemplar as Ideias, ele perde 
sua individualidade para se tornar um e o mesmo com os objetos, a fim de se tornar espelho claro de tais objetos. Cada vez que o gênio detém o foco em um objeto e que esse objeto se torna seu inteiro mundo, deixa de haver algo para além dele. Tem-se aí a experiência mística do gênio.

Ao que nos parece, essa experiência mística do gênio contém em si uma nítida semelhança com o método de conhecimento do espírito livre. Deve-se lembrar que, a fim de obter conhecimento da realidade, o espírito livre tem de encarnar em sua própria pele os valores que a humanidade desenvolveu ao longo de sua história. Cada vez que o espírito livre encarna um valor, identifica-se a ele, já que tal valor torna seu modo de vida passageiro.

O espírito livre perde a sua individualidade, seus valores pessoais para encarnar todos os valores da humanidade. De modo semelhante, o gênio perde a sua individualidade para se tornar um e o mesmo com os objetos. O caminho para o conhecimento do espírito livre é um caminho tão místico quanto o do gênio. Ambos perderam a sua individualidade para chegar a um conhecimento do mundo.

À medida que constantemente encarna as perspectivas de muitos indivíduos, o espírito livre é muitos indivíduos ao mesmo tempo. O mesmo se aplica ao gênio, que se identifica a todos os objetos de contemplação. A exemplo do que se tem com o espírito livre, o gênio olha para as coisas por muitas perspectivas, como se fossem muitos indivíduos, ou, nas próprias palavras de Schopenhauer, "todos criaturas que conhecem". Na verdade, Schopenhauer afirma que, como sujeitos puros de cognição, "continuamos a existir somente como o único olho do mundo a contemplar, assumindo o ponto de vista de todas as criaturas que conhecem" (Schopenhauer, 2010, p. 221).

Outra semelhança entre o espírito livre e o gênio está em que ambos são indivíduos excepcionais, isto é, nem um nem outro age como a maioria das pessoas. Por um lado, enquanto a maior parte das pessoas aceita acriticamente os valores sociais, o espírito livre 
Langone, L.

põe-nos em questão. Por outro lado, diferentemente da maioria das pessoas que são escravas de suas paixões, o gênio é capaz de por algum tempo se livrar de seus próprios desejos e interesses para contemplar as Ideias.

O indivíduo comum, um produto de fábrica da natureza que é feita cada dia aos milhares, não é, como estamos dizendo, nem remotamente capaz de uma atitude plenamente desinteressada (em todo e qualquer sentido do termo), ainda que ele possa de início assumir tal atitude: ainda assim, tal atitude é a de uma contemplação verdadeira. A pessoa é capaz de prestar atenção unicamente a coisas que estabelecem algum tipo de relação com essa vontade, ainda que seja bastante indireta (Schopenhauer, 2010, p. 210-211).

A maior parte das pessoas busca a sua própria vantagem, o seu objetivo único estando em perseguir os seus próprios desejos. Dessa perspectiva, contemplar a vida em si mesma como faz o gênio é perda de tempo. Eles terminam seus afazeres por demais rapidamente e sem muito contemplar um objeto: após ter trazido um objeto por sob um conceito, perdem o interesse por ele.

O gênio, pelo contrário, permite-se um tempo para contemplar a vida enquanto tal. Ao olhar para objetos, não passa tão rapidamente por suas relações com outros objetos, mas anseia por obter acesso à Ideia de cada objeto. Sua cognição não se vê restrita às Ideias de objetos que efetivamente lhe estão presentes. A imaginação sempre lhe permite contemplar todas as cenas possíveis da vida. Assim sendo, a imaginação é uma condição do gênio, mas não vice-versa: pessoas de qualquer gênio que seja podem ser dotadas de um imenso grau de imaginação.

O gênio pode contemplar as Ideias por ser dotado de poderes cognitivos maiores do que o normal. Contudo, apenas temporariamente ele poderá libertar a vontade e viver de acordo com o intelecto. A partir de dado momento, a vontade tornará a assumir o controle do intelecto.

116 | Cad. Nietzsche, Guarulhos/Porto Seguro, v.41, n.1, p. 105-119, janeiro/abril, 2020. 
Em razão desses poderes cognitivos maiores do que o normal, o gênio tem um grão de loucura:

E, uma vez que parte de sua cognição foi subtraída em favor da vontade, durante uma conversa ele não pensará na pessoa com quem estiver falando, por ter bastante vívidas em seu espírito as coisas de que estão a falar: assim, deverão julgar ou narrar de modo por demais objetivo, por seu próprio bem, e falar sobre coisas que seria perspicaz não mencionar etc. Por fim, mostram-se inclinados a monólogos e, de modo geral, podem exibir uma série de fraquezas que na verdade beiram a loucura (Schopenhauer, 2010, p. 213-214).

Para Schopenhauer, a loucura não implica uma falta de razão ou de entendimento: pessoas loucas podem perfeitamente extrair inferências e compreender relações de causa e efeito. Elas compreendem o que está imediatamente presente, mas sua doença lhes afeta a memória: pessoas loucas apresentam lacunas de memória que preencherão com ficções.

Eis aqui outra semelhança entre o gênio e o espírito livre. Ambos apresentam um grão de loucura em comparação com a maioria das pessoas. Lembramos que, com o intuito de expressar seus próprios pensamentos sem despertar repercussões sociais, o espírito livre teve de assumir o disfarce de louco, mas em alguns casos ele efetivamente enlouquece.

Além disso, Nietzsche e Schopenhauer chegam a usar o mesmo termo, schweben (pairar), para fazer referência a espírito livre e gênio, respectivamente. Em particular, ao descrever o estado de paz interior que o gênio alcança quando renuncia a seus desejos, Schopenhauer afirma que, nesse estágio, "a vida e suas formas meramente deslizam (schweben) diante dele, com uma aparência fugidia, como um suave sonho matinal a flutuar por alguém meio desperto, cuja realidade já está a reluzir e já não pode enganar" (Schopenhauer, 2010, p. 417).

Após ter suprimido seus impulsos, nada é capaz de preocupar ou de excitar o seu gênio. Tudo se põe diante dele de modo indiferente: 
Langone, L.

contempla o mundo com uma serenidade profunda, sem apego algum. É como se ele pairasse por sobre o mundo para além de espaço e tempo.

Ao que nos parece, Schopenhauer e Nietzsche querem dizer a mesma coisa com o termo schweben: desapego às coisas materiais. À medida que o gênio as desconsidera para contemplar as Ideias, uma vez tendo trilhado o caminho para o conhecimento, o espírito livre já não se mostra interessado nelas, já não compartilha os valores da maioria. Após terem se libertado das concepções ilusórias em que a maior parte das pessoas acredita, o espírito livre e o gênio só podem mesmo pairar acima delas, na consciência do quanto lhes são independentes.

\title{
Nietzsche's Free Spirit and Schopenhauer's Genius: a Parallelism
}

\begin{abstract}
This article aims to show the similarities between Nietzsche's free spirit and Schopenhauer's genius. First of all, both share a mystical approach to knowledge: they lose their individuality and identify themselves with the objects of knowledge in order to obtain knowledge of the world. Secondly, both figures are associated with madness. Thirdly, the free spirit and the genius are exceptional individuals who unlike the majority of people are no longer attached to worldly matters. They conduct their lives peacefully, hovering over the values in which most people believe, aware of their falsehood.
\end{abstract}

Keywords: art; mystic, experimentation, individuality, will, Ideas. 
O espírito livre de Nietzsche e o gênio de Schopenhauer: um paralelismo

\section{Referências}

NIETZSCHE, F. Sämtliche Werke. Kritische Studienausgabe (vol. 2). Edição organizada por Giorgio Colli e Mazzino Montinari. München/Berlin/New York: Deutscher Taschenbuch Verlag de Gruyter, 1988.

Kritische Studienausgabe (vol. 3). Edição organizada por Giorgio Colli e Mazzino Montinari. München/Berlin/New York: Deutscher Taschenbuch Verlag de Gruyter, 1988.

SCHOPENHAUER, A. The World as Will and Representation. Volume I. Tradução [para o inglês] e edição de Judith Norman, Alistair Welchman, e Christopher Janaway. Cambridge: Cambridge University Press, 2010.

Enviado: 14/10/2019

Aceito: 16/12/2019 